\title{
ESTUDO DA FUNÇÃO HEPÁTICA DE RATOS ESPONTANEAMENTE HIPERTENSOS SUBMETIDOS A DIFERENTES PRESSÕES DE PNEUMOPERITÔNIO COM CO ${ }_{2}{ }^{1}$
}

\author{
Valéria Vieira Chida ${ }^{2}$ \\ Márcia Bento Moreira ${ }^{3}$ \\ Luís Fernando Paes Leme ${ }^{4}$ \\ Djalma José Fagundes ${ }^{5}$ \\ Carlos Eduardo Benetti Ramalho ${ }^{6}$ \\ Neil Ferreira Novo ${ }^{7}$ \\ Edna Frasson de Souza Montero ${ }^{8}$
}

Chida VV, Moreira MB, Leme LFP, Fagundes DJ, Ramalho CEB, Novo NF, Montero EFS. Estudo da função hepática de ratos espontaneamente hipertensos submetidos a diferentes pressões de pneumoperitônio com $\mathrm{CO}_{2}$. Acta Cir.Bras [serial online] 2003 Jan-Fev;18(1). Disponível em URL: http://www.scielo.br/acb.

RESUMO - Objetivo: Avaliar a função hepática de ratos hipertensos submetidos a baixa ou alta pressão de pneumoperitônio. Métodos: Foram utilizados 60 ratos, distribuídos em dois grupos $(\mathrm{n}=$ 30), de acordo com a pressão de pneumoperitônio de 4 e $10 \mathrm{mmHg}$, sendo 15 animais da linhagem EPM-1 Wistar e 15 animais da linhagem SHR. Logo após a pesagem, os animais foram submetidos à anestesia com cetamina e xilazina intramuscular e, em seguida, submetidos a pneumoperitônio, durante 1 hora e desinsuflação por mais 1 hora. Foram coletadas amostras sangüíneas logo após a realização do cateterismo da artéria femoral esquerda, após uma hora de insuflação, assim como, depois de uma hora de desinsuflação. Estas amostras foram encaminhadas para a avaliação das enzimas hepáticas (AST, ALT, DHL) e bilirrubinas (total, direta e indireta). O nível de significância estatístico foi estabelecido em 5\%. Resultados: Com pneumoperitônio de $4 \mathrm{mmHg}$ a AST e ALT apresentaram níveis iniciais menores do que após insuflação e desinsuflação enquanto a DHL, a BT e a BD não se alteraram; em ambas as linhagens. Na pressão de $10 \mathrm{mmHg}$ a AST e a DHL não se alteraram nos ratos normotensos e aumentaram nos hipertensos, a BD não se alterou, a ALT e a BT aumentaram para ambas as linhagens. Conclusão: A função hepática mostrou-se alterada e a medida do tempo após a desinsuflação foi curta para evidenciar uma eventual reversão dessas alterações, tanto nos animais hipertensos, como em animais hígidos.

DESCRITORES - Pneumoperitônio artificial. Ratos endogâmicos SHR. Fígado.

1. Resumo de Tese de Mestrado defendida e aprovada no Programa de Pós-Graduação em Técnica Operatória e Cirurgia Experimental (TOCE) da Universidade Federal de São Paulo - Escola Paulista de Medicina (UNIFESP-EPM).

2. Mestre pelo Programa de Pós-Graduação em Técnica Operatória e Cirurgia Experimental da UNIFESP-EPM.

3. Mestre pelo Programa de Pós-Graduação em Técnica Operatória e Cirurgia Experimental da UNIFESP-EPM.

4. Prof. Dr. pelo Programa de Pós-Graduação em Técnica Operatória e Cirurgia Experimental da UNIFESP-EPM.

5. Professor Coordenador do Programa de Pós-Graduação em Técnica Operatória e Cirurgia Experimental da UNIFESP-EPM.

6. Aluno do Programa de Pós-Graduação em Morfologia da UNIFESP-EPM.

7. Professor Adjunto da Disciplina de Bioestatística do Departamento de Medicina Preventiva da UNIFESP-EPM.

8. Professora Dr $^{\mathrm{a}}$ Orientadora da Tese de Mestrado do Programa de Pós-Graduação de Técnica Operatória e Cirurgia Experimental da UNIFESP-EPM. 


\section{INTRODUÇÃO}

O desenvolvimento da técnica laparoscópica na cirurgia foi tão preponderante que a análise crítica não conseguiu acompanhar no mesmo ritmo ${ }^{(1)}$. Entretanto, a avaliação de uma nova tecnologia representa, mais do que uma curiosidade científica, uma obrigação ética $^{(2)}$.

O emprego da técnica videolaparoscópica, para a realização de procedimentos operatórios, tem sido cada vez mais difundido em todo o mundo. Desta forma, as complicações decorrentes do tipo de gás, do aumento da pressão e do tempo de pneumoperitônio passaram a ser estudadas com a finalidade de verificar uma possível interferência nas funções orgânicas ${ }^{(1,3)}$.

Dentre as complicações, uma das mais abordadas são aquelas decorrentes do aumento da pressão intraabdominal. Entretanto, a maioria das alterações, conseqüentes à queda do débito cardíaco e do fluxo sangüíneo esplâncnico, resultando em isquemia e disfunção orgânica das vísceras abdominais, são transitórias e retornam aos valores normais com a suspensão do pneumoperitônio ${ }^{(3,4,5)}$.

Apesar das modificações serem reversíveis no paciente hígido, a cirurgia videolaparoscópica pode apresentar restrições à sua indicação em pacientes portadores de doenças preexistentes ${ }^{(1,6,7)}$.

Parece não haver consenso na literatura sobre as implicações do pneumoperitônio na função hepática, contudo, têm sido relatado um aumento na atividade das transaminases diretamente proporcional ao aumento da pressão e do tempo de pneumoperitônio ${ }^{(1,3,7)}$.

Por isso, refere-se que não se deve realizar procedimentos laparoscópicos prolongados na vigência de insuficiência hepática grave, ou então que se deve utilizar baixas pressões ou técnica que não envolva insuflação peritoneal ${ }^{(6,7,8)}$.

A repercussão da queda do fluxo sangüíneo hepático na atividade das aminotransferases tem sido estudada, tanto em seres humanos como em animais de experimentação, porém não em associação a uma doença preexistente ${ }^{(3,7,7)}$.

Dentre os estudos em animal de experimentação, encontram-se dois trabalhos que empregam o rato como modelo. Fagundes ${ }^{(10)}$ observou um aumento na atividade das aminotransferases com pressão de pneumoperitônio de $6 \mathrm{mmHg}$. Entretanto, Tsugawa et al. ${ }^{(11)}$, em um estudo comparativo de ratos com hipertensão portal e hígidos, submetidos a pressões progressivamente crescentes de pneumoperitônio de $\mathrm{CO}_{2}$, de 0 a $40 \mathrm{mmHg}$, observaram um aumento das aminotransferases com pressões entre 20 e $30 \mathrm{mmHg}$, ou seja, pressões bastante elevadas. Portanto, torna-se importante, do ponto de vista científico, investigar estas alterações em animais portadores de doenças, que sejam freqüentes nos seres humanos, procurando estabelecer uma interação entre os fatores.

Desta forma, como a hipertensão arterial sistêmica é uma doença de relevância e pode apresentar influência na diminuição do fluxo sangüíneo esplâncnico, em resposta à insuflação peritoneal com aumento da pressão intra-abdominal, decidiu-se utilizar, como modelo animal, o rato portador de hipertensão arterial espontânea, para avaliar o efeito do pneumoperitônio na função hepática.

\section{OBJETIVO}

Estudar a função hepática de ratos espontaneamente hipertensos submetidos a diferentes pressões intraperitoneais.

\section{MÉTODOS}

\section{Amostra}

Foram utilizados 60 ratos machos, adultos, com idade aproximada de 4 meses e com peso variando de 280 a $400 \mathrm{~g}$, sendo 30 ratos da linhagem EPM-1 Wistar e 30 ratos SHR ("Spontaneously Hypertensive Rats") Os animais foram procedentes do Centro de Desenvolvimento de Modelos Experimentais para a Pesquisa em Medicina e Biologia (CEDEME) da UNIFESP-EPM. Os animais permaneceram em ambiente com iluminação natural e temperatura controlada. A dieta foi constituída por ração própria para a espécie e água à vontade. A distribuição dos animais em dois grupos de trinta animais cada, denominados de Grupo $4 \mathrm{mmHg}$ e Grupo $10 \mathrm{mmHg}$ foi aleatória.

GRUPO 4mmHg: 15 animais de cada linhagem (EPM-1 Wistar e SHR) foram submetidos a um pneumoperitônio de $4 \mathrm{mmHg}$ durante 1 hora e desinsuflação por mais 1 hora.

GRUPO 10mmHg: 15 animais de cada linhagem (EPM-1 Wistar e SHR) foram submetidos a um pneumoperitônio de $10 \mathrm{mmHg}$ durante 1 hora e desinsuflação por mais 1 hora.

\section{Procedimentos:}

Após a aferição do peso, os animais foram anestesiados por via intramuscular na face posterior da pata 
traseira direita com associação anestésica de cetamina ${ }^{*}$ e xilazina ${ }^{\dagger}$, na dose de $60 \mathrm{mg}$. $\mathrm{Kg}^{-1}$ e $10 \mathrm{mg}$. $\mathrm{Kg}^{-1}$ de peso corporal, respectivamente. $\mathrm{O}$ plano anestésico foi verificado pela ausência do reflexo de retirada da pata ao estímulo doloroso.

Procedeu-se a imobilização do animal em prancha operatória, em decúbito dorsal horizontal, com seus membros torácicos e pélvicos, fixados em abdução com fita crepe, sobre um colchão térmico para que a temperatura fosse mantida em $37^{\circ} \mathrm{C}$, durante todo o ato operatório.

Realizou-se a tricotomia, anti-sepsia com álcool $70 \%$ e a colocação dos campos esterilizados. Foi dissecada e cateterizada a artéria femoral esquerda com um cateter de polietileno (PE) 50, para medir a pressão arterial média e a coleta de sangue $(1,5 \mathrm{~mL})$. As amostras para análise e controle da ALT, AST, BT, BD, BI e DHL foram colhidas nos seguintes tempos: tempo zero (Pré): antes do pneumoperitônio; tempo 1 (PÓSins): sessenta minutos com pneumoperitônio; tempo 2 (PÓSdes): sessenta minutos após a desinsuflação. O cateter foi heparinizado $(250 \mathrm{~mL} \mathrm{NaCl}$ a $0,9 \%$ e 1,0 $\mathrm{mL}$ de heparina? - 5000 UI..

A seguir, foi realizada uma incisão abdominal infraumbilical, de $5 \mathrm{~mm}$ de comprimento e introdução da agulha de Veress. A agulha transfixava uma rolha de borracha deixando um segmento de $2 \mathrm{~cm}$ para limitar o seu aprofundamento na cavidade abdominal. Após a introdução da agulha na cavidade abdominal, procedeuse a aspiração com seringa e a prova da gota de soro, com intuito de certificar-se que a agulha estava na cavidade abdominal e não ocorrera lesão de alguma víscera abdominal.

Realizada com insuflador laparoscópico a introdução de 0,5 a 1,0 litro de $\mathrm{CO}_{2}$ por minuto, sem préaquecimento, até a estabilização da pressão, conforme os grupos, em $4 \mathrm{mmHg}$ ou $10 \mathrm{mmHg}$. Manteve-se a pressão pré-determinada durante o tempo de sessenta minutos.

Ao final dos sessenta minutos a cavidade abdominal foi totalmente desinsuflada, pela própria agulha de Veresss. Após sessenta minutos da desinsuflação, todos os animais sob efeito anestésico foram submetidos à eutanásia por exsangüinação, após a última coleta de sangue.

* Cetamina para uso veterinário

$\uparrow \quad$ Xilazina para uso veterinário.
Para análise dos resultados foram aplicados os seguintes testes não paramétricos, levando-se em consideração a natureza das variáveis estudadas ou a variabilidade das medidas efetuadas. Foram aplicados os seguintes testes estatísticos:

1-Análise de variância por postos Friedman ${ }^{(12)}$, com a finalidade de comparar os períodos Pré, PÓSins e PÓSdes para cada variável estudada, para cada grupo de ratos separadamente. Esta análise também foi empregada para comparar os valores do $\Delta \%$ ins, $\Sigma \%$ des $\Delta \%$ e total calculados:

$$
\begin{gathered}
\Delta \% \text { ins }=\frac{\text { PÓSins }- \text { Pré }}{\text { Pré }} 100 \\
\Delta \% \text { des }=\frac{\text { PÓSdes }- \text { PÓSins }}{\text { PÓSins }} 100 \\
\Delta \% \text { total }=\frac{\text { PÓSdes }- \text { Pré }}{\text { Pré }} \times 100
\end{gathered}
$$

Onde $\Delta \%$ ins é resultante dos valores obtidos após o cateterismo arterial e após 1 hora de pneumoperitônio, $\Delta \%$ des é resultante dos valores obtidos após 1 hora de pneumoperitônio e 1 hora de desinsuflação e $\Delta \%$ total é resultante dos valores obtidos após o cateterismo arterial e após 1 hora de desinsuflação.

1- Teste de Mann- Whitney ${ }^{(12)}$ para comparar os resultados obtidos do $\Delta \%$ no grupo EPM-1 Wistar em relação ao grupo SHR para cada variável estudada e para $\Delta$ ins, $\Delta$ des e $\Delta \%$ total, separadamente.

Fixou-se em 0,05 o nível de rejeição da hipótese de nulidade, assinalando-se com um asterisco os valores significantes.

\section{RESULTADOS}

Na tabela 1 pode-se observar que com pneumoperitônio de $4 \mathrm{mmHg}$, a AST e ALT apresentaram níveis iniciais menores do que após insuflação e desinsuflação (Figuras 1 e 2) enquanto a DHL, a BT e a BD não se alteraram; em ambas as linhagens. Na pressão de $10 \mathrm{mmHg}$ a AST e a DHL apresentaram forte tendência de elevação nos ratos normotensos, aumentando de forma significante nos hipertensos; a BD não se alterou, a ALT e a BT aumentaram para ambas as linhagens (Tabela 1- Figuras 3 e 4). 
TABELA 1 -Enzimas Hepáticas e PAM

\begin{tabular}{|c|c|c|c|c|c|c|c|}
\hline \multicolumn{8}{|c|}{ Pressão de pneumoperitônio (mmHg) } \\
\hline & & \multicolumn{3}{|c|}{4} & \multicolumn{3}{|c|}{10} \\
\hline & & Pré & PÓS ins & PÓS des & Pré & PÓS ins & PÓS des \\
\hline AST & $\mathrm{W}$ & 79 & 128 & 137 & 61 & 95 & 125 \\
\hline $\mathrm{U} / \mathrm{L}$ & $\mathrm{S}$ & 125 & 166 & 180 & 100 & 196 & 217 \\
\hline ALT & $\mathrm{W}$ & 57 & 103 & 107 & 54 & 68 & 108 \\
\hline $\mathrm{U} / \mathrm{L}$ & $\mathrm{S}$ & 68 & 114 & 130 & 76 & 112 & 217 \\
\hline DHL & $\mathrm{W}$ & 297 & 308 & 320 & 249 & 376 & 405 \\
\hline $\mathrm{U} / \mathrm{L}$ & $\mathrm{S}$ & 276 & 320 & 299 & 201 & 290 & 417 \\
\hline BT & $\mathrm{W}$ & 4,5 & 4,3 & 6,0 & 2,6 & 5,7 & 9,0 \\
\hline $\mathrm{mg} / \mathrm{dL}$ & $\mathrm{S}$ & 1,6 & 1,7 & 4,1 & 2,0 & 4,0 & 3,9 \\
\hline BI & $\mathrm{W}$ & 4,0 & 4,0 & 5,4 & 2,3 & 5,4 & 8,0 \\
\hline $\mathrm{mg} / \mathrm{dL}$ & $\mathrm{S}$ & 1,4 & 1,4 & 3,6 & 1,6 & 4,1 & 3,2 \\
\hline PAM & $\mathrm{W}$ & 110 & 100 & 95 & 100 & 110 & 105 \\
\hline $\mathrm{mmHg}$ & $\mathrm{S}$ & 140 & 145 & 135 & 130 & 125 & 130 \\
\hline
\end{tabular}

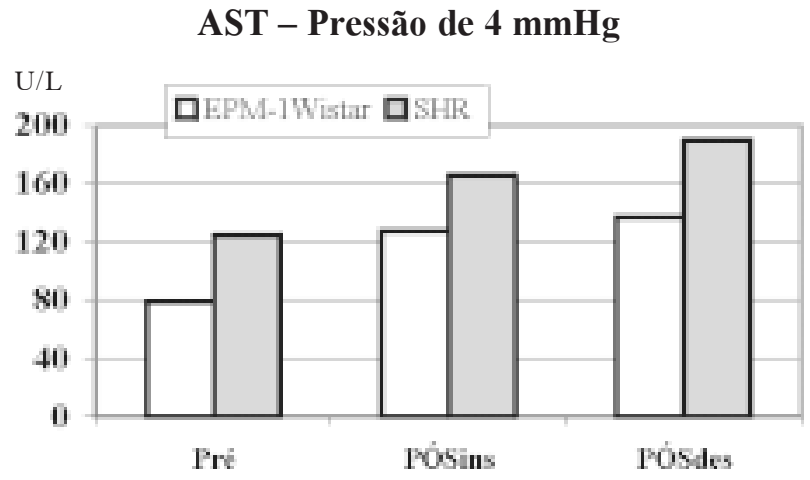

FIGURA 1- Níveis sangüíneos de AST, representados pelas medianas dos valores, para cada linhagem de rato, nos diferentes momentos de avaliação, com uma pressão de $4 \mathrm{mmHg}$ de pneumoperitônio.

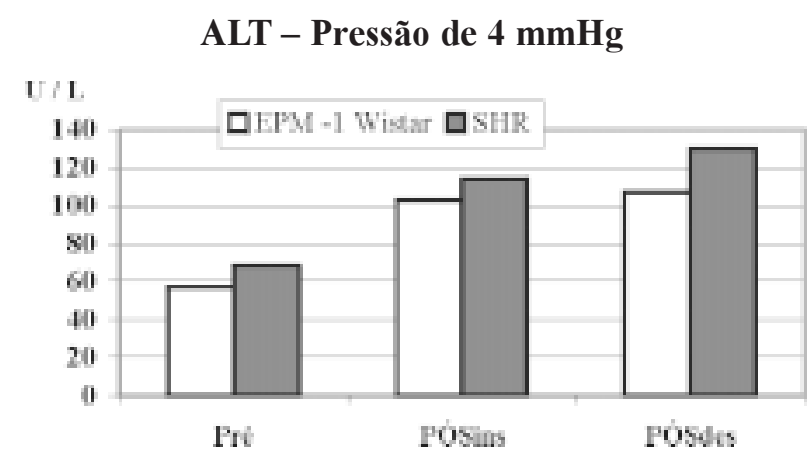

FIGURA 2- Níveis sangüíneos de ALT, representados pelas medianas dos valores, para cada linhagem de rato, nos diferentes momentos de avaliação, com uma pressão de $4 \mathrm{mmHg}$ de pneumoperitônio.
Desta forma, verificou-se elevação progressiva da AST nos períodos de estudo, em ambas as pressões de pneumoperitônio estudadas, para o rato portador de hipertensão arterial, entretanto, para o rato normotenso este aumento foi significante somente na presença de baixa pressão de pneumoperitônio. Os valores de bilirrubina direta não mostraram alteração em nenhuma das pressões estudadas de pneumoperitônio.

\section{AST - Pressão de 10 mmHg}

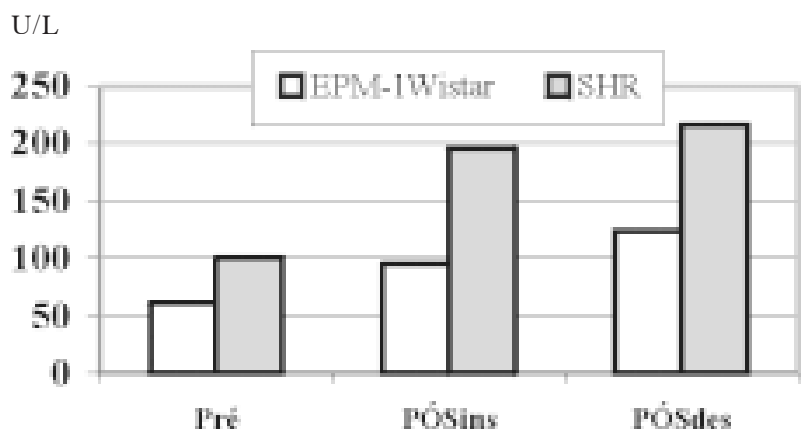

FIGURA 3- Níveis sangüíneos de AST, representados pelas medianas dos valores, para cada linhagem de rato, nos diferentes momentos de avaliação, com uma pressão de $10 \mathrm{mmHg}$ de pneumoperitônio. 


\section{ALT - Pressão de 10 mmHg}

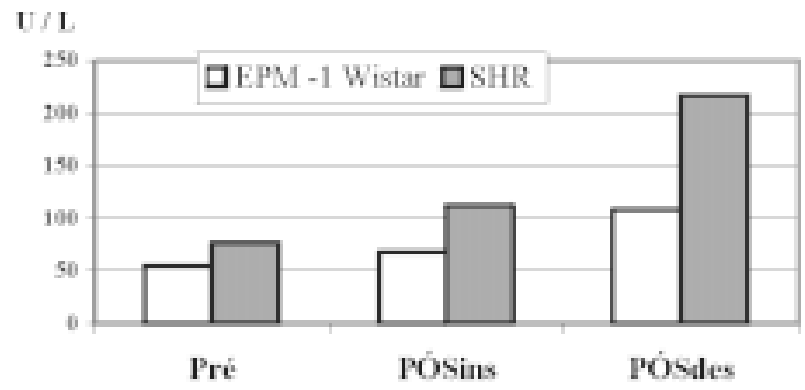

FIGURA 4- Níveis sangüíneos de ALT, representados pelas medianas dos valores, para cada linhagem de rato, nos diferentes momentos de avaliação, com uma pressão de $10 \mathrm{mmHg}$ de pneumoperitônio.

Entretanto, a bilirrubina total apresentou-se elevada, às custas de bilirrubina indireta, para ambas as linhagens, somente na pressão mais elevada de pneumoperitônio. Este parâmetro retratou uma alteração funcional do fígado com a pressão mais elevada de pneumoperitônio, assim como a ALT, para os ratos portadores ou não de hipertensão arterial. A DHL apresentou alteração somente para os animais hipertensos na pressão intraabdominal mais elevada de pneumoperitônio.

\section{DISCUSSÃO}

A experiência adquirida com a videocirurgia despertou o interesse de cirurgiões e pesquisadores em estudar, além das vantagens qualitativas, como alta hospitalar precoce e menor intensidade de dor pósoperatória, os benefícios e malefícios quantitativos deste novo procedimento operatório ${ }^{(13)}$.

O emprego de procedimentos operatórios por videocirurgia é crescente e requer a introdução de um gás na cavidade peritoneal e o aumento agudo da pressão intra-abdominal, ambas as manobras podem apresentar efeito secundário, algumas vezes, indesejáveis.

$\mathrm{O}$ efeito adverso do aumento da pressão intraabdominal em conseqüência da insuflação de gás, para a realização do pneumoperitônio, na função cardíaca, pulmonar e renal, além da diminuição do fluxo sangüíneo esplâncnico, é relatada tanto em trabalhos clínicos como experimentais ${ }^{(5,14)}$.

Encontram-se na literatura, relatos das alterações hemodinâmicas devido ao pneumoperitônio. Estas alterações estão relacionadas à diminuição do retorno venoso sangüíneo e ao aumento da resistência vascular periférica, resultando na redução do volume sistólico final e do débito cardíaco ${ }^{(15,16,17)}$. Apesar das modifica- ções serem reversíveis no paciente normotenso, a cirurgia videolaparoscópica pode apresentar restrições à sua indicação em pacientes portadores de doenças preexistentes $^{(1,6,7)}$.

Dentre os experimentos com modelo animal de doença para a avaliação do efeito do pneumoperitônio, encontra-se o estudo realizado em modelo canino de doença pulmonar obstrutiva crônica que mostrou mudanças hemodinâmicas como aumento do débito cardíaco decorrente da insuflação peritoneal, independentemente do gás utilizado. Ishizaki et al. ${ }^{(18)}$ desenvolveram estudo comparativo entre os gases, dióxido de carbono e hélio, na realização do pneumoperitônio, em suínos. Observaram que o $\mathrm{CO}_{2}$ promoveu uma diminuição do débito cardíaco e um discreto aumento da freqüência cardíaca, em relação ao outro gás ${ }^{(19)}$.

Outro modelo animal de doença utilizado, em porcos, foi o choque hemorrágico, para a avaliação do pneumoperitônio, mostrando que neste caso, a hipercarbia se deve mais ao choque do que à absorção transperitoneal de $\mathrm{CO}_{2}^{(15)}$.

Tsugawa et al. ${ }^{(11)}$ propuseram um modelo de hipertensão portal em ratos para estudo dos efeitos do pneumoperitônio, sugerindo que pressão de pneumoperitônio abaixo de $10 \mathrm{mmHg}$ não apresenta risco para portadores de hipertensão portal.

Levando-se em conta que o animal de pequeno porte apresenta algumas vantagens como animal de experimentação ${ }^{(10,20,21)}$, Berguer et al. ${ }^{(22)}$ propuseram o rato como modelo experimental para a videolaparoscopia, no início dos anos 90. Estes autores sugeriram que os conhecimentos das respostas fisiológicas do rato facilitariam a investigação dos efeitos do pneumoperitônio. Desenvolvendo as primeiras pesquisas em videocirurgia, empregando o rato como animal de experimentação, em nosso meio, Goldenberg et al. ${ }^{(23)}$ propuseram a videolaparoscopia em animais de pequeno porte, ressaltando a facilidade de manutenção do animal para estudos crônicos.

A partir dessas investigações, vêm sendo desenvolvidos experimentos para elucidação dos problemas inerentes a videocirurgia, empregando o animal de pequeno porte, em nosso laboratório de pesquisa da Disciplina de Técnica Operatória e Cirurgia Experimental. Desta forma, experimentos para estudo das alterações hemodinâmicas ${ }^{(24)}$, do fluxo sangüíneo esplâncnico, translocação bacteriana ${ }^{(25,26)} \mathrm{e}$, até mesmo, para o estudo de modelo crônico de precondicionamento isquêmico do estômago ${ }^{(27)}$ foram realizados em associação ao pneumoperitônio. Esta tese está inserida nesta linha de pesquisa, empregando o modelo animal de doença. 
A hipertensão arterial sistêmica é uma doença de relevância clínica, uma vez que acomete grande parte da população. Por outro lado, a videocirurgia é um procedimento operatório que tem sido cada vez mais difundido, com indução de menor resposta inflamatória, endócrina e metabólica ao trauma operatório quando comparada à cirurgia convencional.

A indicação de tratamento operatório por videocirurgia em pacientes hipertensos é, portanto, um acontecimento freqüente e as intercorrências desta associação são passíveis de investigação para estabelecer as suas eventuais conseqüências.

Desta forma, visou-se investigar alterações decorrentes do aumento da pressão intraperitoneal, em conseqüência do pneumoperitônio, utilizando o rato portador de hipertensão arterial espontânea, procurando estabelecer uma relação de causa e efeito.

A anestesia empregada proporciona bom plano anestésico para a realização de operações de duração média, promovendo analgesia e hipnose. Em trabalho desenvolvido no nosso laboratório de pesquisa, observou-se que a associação da cetamina e da xilazina, para a realização de procedimentos videolaparoscópicos em ratos, proporciona melhor estabilidade hemodinâmica, quando comparado ao tiopental sódico ${ }^{(21)}$. Desta forma, optou-se por esta associação de drogas para a anestesia dos animais.

As pressões do pneumoperitônio escolhidas levaram em consideração um nível convencional tido como padrão e potencialmente não deletério, de $4 \mathrm{mmHg}$ e outro nível de $10 \mathrm{mmHg}$, considerado como um nível levado de pressão e, potencialmente, mais deletério ao organismo.

As provas funcionais do fígado permitiram avaliar a ocorrência de disfunção orgânica, pela alteração dos seus níveis séricos. As enzimas que, principalmente, se alteram são as aminotransferases, fosfatase alcalina, gamaglutamil transpeptidase e a dehidrogenase lática. A aspartato aminotransferase está presente em diferentes tecidos, inclusive no fígado. Na presença de dano celular agudo no fígado, observam-se níveis elevados. A alanina aminotransferase é uma enzima mais específica para a avaliação de dano hepático, pois o conteúdo desta enzima no fígado excede, em muito, a concentração em outros tecidos. A sua elevação acompanha o dano hepatocelular agudo. A dehidrogenase lática é uma enzima pouco específica, pois está presente no citoplasma das células de vários tecidos do organismo.

Desta forma, tomando-se por base que a ALT é uma enzima mais específica para avaliação da lesão hepática e observando-se que esta enzima apresentou uma elevação progressiva, mesmo após a desinsuflação do pneumoperitônio, nos períodos de estudo, para ambas as linhagens de rato, independentemente da pressão de pneumoperitônio, pode-se afirmar que houve alteração funcional do fígado. Esta alteração pode ser explicada pela diminuição do fluxo sangüíneo porta durante o pneumoperitônio, seja por compressão vascular ${ }^{(18)}$, seja por diminuição do retorno venoso, promovidos pela pressão intra-abdominal elevada. Em experimento com ratos, Fagundes ${ }^{(10)}$ não observou aumento significante desta enzima, apesar de haver uma tendência à elevação, com pressões fisiológicas de pneumoperitônio. Este achado poderia ser explicado pelo tamanho da amostra e pela variabilidade desse parâmetro.

Com relação a AST, verificou-se elevação progressiva nos períodos de observação, em ambas as pressões de pneumoperitônio estudadas, para o rato portador de hipertensão arterial, entretanto para o rato normotenso este aumento foi significante somente na presença de baixa pressão de pneumoperitônio. Fagundes ${ }^{(10)}$ relatou um aumento dos níveis de AST com a pressão de $6 \mathrm{mmHg}$, apesar de haver tendência a aumentar com a pressão mais baixa.

A DHL apresentou alteração somente para os animais hipertensos na pressão intra-abdominal mais elevada de pneumoperitônio. Talvez seja porque, apesar de ocorrer alteração funcional não haja morte celular importante, que seria expressa com aumento importante desta enzima.

Os valores de bilirrubina direta não mostraram alteração em nenhuma das pressões estudadas de pneumoperitônio. Entretanto, a bilirrubina total apresentou-se elevada, às custas de bilirrubina indireta, para ambas as linhagens, somente na pressão mais elevada de pneumoperitônio. Este parâmetro retratou uma alteração funcional do fígado com a pressão mais elevada de pneumoperitônio, assim como a ALT, para os ratos portadores ou não de hipertensão arterial.

Halevy et al. ${ }^{(9)}$ relataram, em estudo clínico, que aumentos significantes das aminotransferases ocorreram em pacientes submetidos à colecistectomia laparoscópica, entretanto, retornando aos níveis basais até 72 horas após o procedimento. Morino et al. ${ }^{(7)}$, em pesquisa clínica, referiram que as alterações de função hepática durante procedimentos laparoscópicos, eram decorrentes da duração e do nível de pressão intra-abdominal. Estes autores ${ }^{(7)}$ avaliaram as aminotransferases e a bilirrubina, observando retorno aos níveis iniciais entre 24 e 48 horas.

Pouco se encontra na literatura sobre os efeitos do pneumoperitônio sobre a função hepática ${ }^{(7,9,10)}$, sendo que somente um estudo e foi realizado em animais ${ }^{(10)}$. Entretanto, existem vários trabalhos que avaliam o fluxo sangüíneo portal, da artéria hepática e da microcirculação hepática na vigência de pneumoperitônio ${ }^{(5,23,27,28)}$.

Os efeitos do aumento da pressão intra-abdominal na circulação hepática foram estudados em alguns 
modelos experimentais ${ }^{(2,6,30,31)}$. Diebel et al. ${ }^{(28)}$ estudaram a sua repercussão sobre a perfusão hepática, em suínos, mostrando uma redução em função do aumento da pressão intra-abdominal. As mudanças da microcirculação hepática observada relacionaram-se, principalmente, às alterações do fluxo sangüíneo portal. Relata-se que as alterações no fluxo sangüíneo hepático durante o aumento da pressão intra-abdominal são decorrentes, particularmente, da resistência vascular mesentérica ${ }^{(29)}$.

Além disso, parece haver também influência hormonal, como a elevação da vasopressina relatada por Punnonem et $\mathrm{al}^{(32)}$, em pacientes submetidas à laparoscopia ginecológica. Mann et al. ${ }^{(31)}$, em estudo experimental com porcos, mostraram que a insuflação com $\mathrm{CO}_{2}$ promoveu a liberação de vasopressina, o que, por sua vez, levou a distúrbios hemodinâmicos. Estes autores concluíram que as mudanças hemodinâmicas observadas durante o pneumoperitônio de $\mathrm{CO}_{2}$ estavam relacionadas aos efeitos bioquímicos do gás $\mathrm{CO}_{2}$ e que eram, primariamente, mediados pelo aumento da concentração plasmática de vasopressina ${ }^{(22)}$

Para a realização de procedimentos videolaparoscópicos, além do aumento da pressão intra-abdominal, inclui-se a influência dos gases utilizados na promoção do pneumoperitônio. Com a utilização do dióxido de carbono, está descrita a ocorrência de hipercapnia ${ }^{(15)}$, a qual também deve ser levada em conta na avaliação da redução do fluxo sangüíneo hepático.

Existem vários pontos a serem investigados com relação ao pneumoperitônio e a sua influência na fisiologia hepática em pacientes hígidos e principalmente em pacientes hipertensos.

O modelo experimental em ratos, aqui proposto mostrou que, de algum modo, a função hepática se altera na vigência do pneumoperitônio o que ficou demonstrado pela alteração específica da ALT em ambas as linhagens (normo e hipertensos). Esta alteração manteve-se após 1 hora da desinsuflação. É provável que esta alteração seja transitória e reversível em tempos maiores de observação, após a desinsuflação.

A alterações da ALT assim como da bilirrubina total mostraram que, em um regime de pressão alta de pneumoperitônio $(10 \mathrm{mmHg})$, as alterações funcionais hepáticas são mais evidentes, independente da linhagem do animal.

O mecanismo de ação que leva o pneumoperitônio a provocar alterações funcionais hepáticas deve ser associado às modificações na perfusão esplâncnica e hepática, quer pela ação direta da pressão sobre os vasos hepáticos quer pela estase esplâncnica.

O modelo abre perspectivas para a continuação do estudo entre as diversas correlações que podem ser feitas entre a perfusão hepática (arterial, portal ou microcirculação), o pneumoperitônio e a hipertensão arterial sistêmica.

\section{CONCLUSÃO}

A função hepática de ratos espontaneamente hipertensos apresenta deterioração, sob o efeito de pneumoperitônio, de modo semelhante aos ratos normotensos. Além disso, o tempo de desinsuflação não foi suficiente para que mostrar uma eventual reversão das alterações ocorridas.

\section{REFERÊNCIAS}

1. Ulla HH, Manfred N, Hans T. CO2 pneumoperitoneum: what we need to know. World J Surg 1999; 23:794-800.

2. Kuhn T. Estrutura das revoluções científicas. 5ed. Editora Perfectiva; 1999. p 25-6.

3. Eleftheriadis E, Kotzampassi K, Botsios D, Tzartinoglou E, Farmakis H, Dadoukis J. Splanchnic ischemia during laparoscopic cholecystectomy. Surg Endosc 1996; 10:324-6.

4. Windberger BU, Auer RM, Keplinger F, Längle F, Heinze G, Schindl M, Lousert MU. The role of intra-abdominal pressure on splanchnic and pulmonary hemodynamic and metabolic changes during carbon dioxide pneumoperitoneum. Gastroint Endose 1999; 49:84-91

5. Caldwell CB, Ricotta JJ. Changes in visceral blood flow with elevated intra-abdominal pressure. J Surg Res 1987; 43:14:20.

6. Hashikura Y, Kawasaki S, Munakata Y, Hashimoto S, Hayashi $\mathrm{K}$, Makuuchi M. Effects of peritoneal insufflation on hepatic and renal blood flow. Surg Endosc 1994; 8:759-61.

7. Morino M, Giraudo G, Festa V. Alterations in hepatic function during laparoscopic surgery: an experimental clinical study. Surg Endosc 1998; 7:968-72.

8. Takagi S. Hepatic and portal vein blood flow during carbon dioxide pneumoperitoneum for laparoscopic hepatectomy. Surg Endose 1998; 12:427-31.

9. Halevy A, Gold-Deutch R, Negri M, Lin G, Shlamkovich N, Evans S, Cotariu D, Scapa E, Bahar M, Sackier JM. Are elevated liver enzymes and bilirubin levels significant after laparoscopic cholecystectomy in the absence of bile duct injury. Ann Surg 1994; 219 4:362-4.

10. Fagundes MAV. Efeito do pneumoperitônio no rato [Tese Mestrado]. Universidade Federal de São Paulo - Escola Paulista de Medicina; 1999

11. Tsugawa K, Makoto H, Migou S, Tanoue K, Kishihara F, Kawanaka H, Sugimachi K. The effect carbon dioxide pneumoperitoneum on the portal hemodynamics in a portal hypertensive rat model. Surg Laparosc Endosc Percut Tech 1999; 5:338-47.

12. Siegel S, Castellan Jr NJ. Noronparametric statistics. 2ed. NewYork: Mac Graw Hill Int Ed; 1988

13. Goldenberg S, Goldenberg A, Deutsch RC, Cohen VR. Avanços em cirurgia videolaparoscópica. São Paulo: Reichmann \& Affonso Editores RA; 1999. p 3-6.

14. Diebel NL, Wilson RF, Dulchavsky AS, Saxe J. Effect of increased intra-abdominal pressure on mesenteric arterial and intestinal mucosal blood flow. J Trauma 1992; 33:279-83.

15. Leighton T, Pianim N, Liu S, Kono M, Lleein S, Bongard F. Effects of hypercarbia during experimental pneumoperitoneum. Am Surg 1992; 58:717-21.

16. Leighton T, Liu S, Bongard FS. Comparative cardiopulmonary effects of carbon dioxide versus helium pneumoperitoneum Surgery $1993 ; 113: 527-31$.

17 Safran DB, Orlando R. Physiologic effects of pneumoperitoneum. Am J Surg 1994; 167:281-6.

18. Ishizaki Y, Shimonura K, Abe H, Ohtomo Y, Idezuki Y. Changes in splanchnic blood flow and cardiovascular effects following peritone insuflation of carbon dioxide. Surg Endosc 1987; 7:420-3. 
19. Olerud S. Experimental studies on portal circulation at increased intra-abdominal pressure. Acta Physiol Scand 1953;(suppl 109): $1-95$

20 Andrus $\mathrm{CH}$, Wittgen CM, Naunheim KS. Anesthaetic and physiological changes during laparoscopy and thoracoscop: the surgeons view. Semin Laparosc Surg 1994; 1:228-40.

21. Leão JQS, Goldenberg A, Manna MCB., Zanchet DJ, Montero EFS Parâmetros hemodinâmicos e gasimétricos de ratos submetidos a pneumoperitônio sob ação de diferentes anestésicos injetáveis. Acta Cir Bras 1997; 12:2-8.

22. Berguer R, Gutt CN. Laparoscopic colon surgery in a rat model: a preliminary report. Surg Endosc 1994; 8:1195-7.

23. Goldenberg A, Lobo E, Marcondes EJ, Louzada M, Barbosa CDL. Proposição de videolaparoscopia em ratos. Acta Cir Bras 1997; 12:219-20.

24. Silva FOAB. Avaliação hemodinâmica de ratos, com infarto cardíaco crônico, submetidos ao pneumoperitônio com $\mathrm{CO}_{2}$. [Tese - Mestrado]. Universidade Federal de São Paulo - Escola Paulista de Medicina; 2001.

25. Silva Jr JB. Avaliação da Peritonite Bacteriana Induzida em Ratos Submetidos a Pressões Elevadas de Pneumoperitônio. [Tese - Mestrado]. Universidade Federal de São Paulo - Escola Paulista de Medicina; 2001.

26. Tanaka TM. Influência do pneumoperitônio associado à peritonite bacteriana na indução da resposta inflamatória. Estudo experimental em ratos. [Tese- Doutorado]. Universidade Federal de São Paulo - Escola Paulista de Medicina; 2002
27. Paes Leme LF. Condicionamento isquêmico do estômago por videolaparoscopia Estudo experimental em ratos [TeseDoutorado]. Universidade Federal de São Paulo - Escola Paulista de Medicina; 2001.

28. Diebel LN, Wilson RF, Dulchavsky AS, Saxe J. Effect of increased intra-abdominal pressure on hepatic arterial, portal venous, and hepatic microcirculatory blood flow. J Trauma 1992; 33:279-83

29. Richardson OD, Withrington. Liver blood flow. Effects of drugs and hormones on liver blood flow. Gastroenterology $1981 ; 81: 6$.

30. Kotzampassi K, Kapanidis N, Eleftheriadis E. Hemodinamic events in the peritoneal environment during pneumoperitoneum in dogs. Surg Endosc 1997; 7:494-9.

31. Shuto K, Kitano S, Yoshida T, Bandoh, Mitarai Y, Kobayashi M. Hemodinamic and arterial blood gas changes during carbon dioxide and helium pneumoperitoneum in pig. Surg Endosc 1998; 9:1173-8.

32. Punnonem R, Viinamaki O. Vasopressin release during laparoscopy: role of increased intra-abdominal pressure. Lancet 1982; 8264:175-6.

33. Mann C, Bocarra G, Pouzeratte Y, Eliet J, Serradel-le GC, Vergnes C, Bichet GD, Guillon G, Fabre MJ, Colson P. The relationship among carbon dioxide pneumoperitoneum, vasopressin release, and hemodynamic changes. Anesthes Res Soc 1999; 89:278-83.

Chida VV, Moreira MB, Leme LFP, Fagundes DJ, Ramalho CEB, Novo NF, Montero EFS. Study of the hepatic function in spontaneously hipertensive rats submitted to different pressures of the $\mathrm{CO}_{2}$ pneumoperitoneum. Acta Cir.Bras [serial online] $2003 \mathrm{Jan}-\mathrm{Feb}$; 18(1). Available from URL: http:// www.scielo.br/acb.

ABSTRACT - Purpose: In order to determine the behavior of the hepatic function in spontaneously hipertensive Rats Which underiwent low pressure and high pressure pneumoperitoneum. Methods: 60 rats were studied two groups of 30 rats, each formed by 15 Wistar EPM-1 and 15 SHR, were subjmitted to $4 \mathrm{mmHg}$ and $10 \mathrm{mmHg}$ pressure respectively, for 1 hour plus peritoneal pressure normalization time of 1 hour. Immediately after being weighed the rats were given an anesthetic (cetamine and xylazine) intramuscular. Blood samples for hepatic function evaluation were taken immediately after the insertion of a catheter in the left femural artery as well as after 1 hour insufflation and after the one-hour pressure normalization. The significance coeficient was $5 \%$. Results: Animals submitted to $4 \mathrm{mmHg}$ pressure had inicial AST and ALT levels lower than after insuflation and after pressure normalization. DHL, BT and BD levels did not change for both strains. Animals submitte to $10 \mathrm{mmHg}$ pressure AST and DHL levels modification for normotensive rats but increased for hypertensive ones; BD did not change; ALT and BT changed for Wistar and SHR. Conclusion: Our study shows that pneumoperitoneum has changed the hepatic function of the animals and suggests that one-hour peritoneal pressure normalization seems to be too short to allow hepatic function normalization in both hyper and normotensive animals.

KEY WORDS - Pneumoperitoneum, artificial. Rats, inbred SHR. Liver.

Conflito de interesse: nenhum

Correspondência:

Fonte de financiamento: nenhuma

Edna Frasson de Souza Montero

Al. Espada, 134 - Alphaville

0654-395 - Santana de Parnaíba - SP

Tel: (11)4153-8100 - efsmontero.dcir@epm.br

Data do recebimento: 23/09/2002

Data da revisão: $12 / 10 / 2002$

Data da aprovação: 28/10/2002 